\title{
IN VITRO BIOLOGICAL STUDY OF SEVEN NEPALESE MEDICINAL PLANTS AND ISOLATION OF CHEMICAL CONSTITUENTS FROM CISSAMPELOS PAREIRA
}

\author{
MD AMIT, KHAGA RAJ SHARMA* \\ Central Department of Chemistry, Tribhuvan University, Kirtipur, Kathmandu, Nepal. Email: khagaraj_sharma33@yahoo.com
}

Received: 18 May 2020, Revised and Accepted: 22 June 2020

ABSTRACT

Objective: This study aimed to investigate the phytochemical analysis and biological activities of methanol extracts of seven medicinal plants such as Anisomeles indica, Achyranthes bidentata, Sphenomeris chinensis, Cleistocalyx operculatus, Malvaviscus arboreus, Cissampelos pareira, and Tectaria coadunate collected from Tanahun district of Nepal.

Methods: Phytochemical analysis was performed by color differentiation methods adopting the standard protocol. Antioxidant activity of plant extracts was evaluated by 2,2-diphenyl-1-picrylhydrazyl radical scavenging assay. Flavonoid content was estimated by aluminum chloride colorimetric method. Antidiabetic activity was evaluated by $\alpha$-amylase inhibition assay where acarbose was used as standard. Toxic effect was studied by brine shrimp bioassay.

Results: Phytochemical analysis showed the presence of alkaloids, polyphenols, flavonoids glycoside, and terpenoid in most of the extracts. T. coadunate and C. pareira exhibited high antioxidant activity with $\mathrm{IC}_{50} 41.84$ and $52.03 \mu \mathrm{g} / \mathrm{ml}$, respectively. Whereas, the plant extracts of Malvaviscus arboretum, $S$. chinensis, and A. bidentata exhibited moderate antioxidant activity with $\mathrm{IC}_{50} 76.07,81.05$, and $89.93 \mu \mathrm{g} / \mathrm{ml}$, respectively. The result of flavonoid content showed the values ranged $A$. indica (1.84 mg quercetin equivalent per gram [mg QE/g]) to $A$. bidentata (5.93 mg QE/g). C. pareira and $S$. chinensis exhibited the highest $\alpha$ amylase inhibition activity with $\mathrm{IC}_{50} 471.68$ and $517.59 \mu \mathrm{g} / \mathrm{ml}$, respectively. Whereas, $A$. indica and M. arboreus showed moderate activity with $\mathrm{IC}_{50} 626.12$ and $952.39 \mu \mathrm{g} / \mathrm{ml}$, respectively. C. pareira exhibited against Staphylococcus aureus (ATCC 25923) with a zone of inhibition $12 \mathrm{~mm} /$ well, and Escherichia coli (ATCC 25922) $9 \mathrm{~mm} /$ well but, T. coadunate showed $14 \mathrm{~mm} /$ well against S. aureus. The plant extracts of $A$. bidentata and $C$. operculatus showed toxic effect against newly hatched brine shrimp larvae. The chemical compounds isolated from $C$. pareira indicated by gas chromatography-mass spectrometry analysis were 3-isopropoxy-1,1,1,7,7,7-hexamethyl-3,5,5-tris(trimethylsiloxy) tetrasiloxane, alpha-tocopherol, pentadecanoic acid, and 4,22-stigmastadiene-3-one. The major compound was indicated by percent peak area and base $\mathrm{m} / \mathrm{z}$ value as alpha-tocopherol.

Conclusion: Present study revealed that plant extracts are the potential source of antioxidant, antidiabetic, and antibacterial agents showing different biological activities. The results of this study provide partial scientific support for the traditional application of medicinal plants to cure diabetes and infectious diseases, although further studies are needed to assess the mechanism of action.

Keywords: Phytochemical, Antioxidant, Antimicrobial, Cytotoxic, Antidiabetic, 2,2-diphenyl-1-picrylhydrazyl, Zone of inhibition, Medicinal plant.

(C) 2020 The Authors. Published by Innovare Academic Sciences Pvt Ltd. This is an open access article under the CC BY license (http://creativecommons. org/licenses/by/4. 0/) DOI: http://dx.doi.org/10.22159/ajpcr.2020.v13i9.38370

\section{INTRODUCTION}

Nepal is rich in biodiversity and accommodates all types of world agroclimate for cultivation and conservation of a wide variety of biological resources. Peoples have been using medicinal plants for many years to relieve and cure of simple to life-threatening diseases is mentioned in Ayurveda as the oldest repository of human knowledge as the foundation of medicinal science. The use of herbal medicines for the treatment of different diseases has the least side effect and high efficacy. The use of plants as medicines and as food is gaining popularity not only in the developing countries but also in many of the developed countries. The medicinal plants of Nepal may be considered one of the important natural resources to enhance the economic status of the country [1]. Peoples of different communities have been using medicinal plants as anticancer, antidiabetic, antioxidant, and as an anti-infective for many years with limited scientific validation. An antioxidant is a molecule capable of inhibiting the oxidation of other molecules. Oxidation reaction can produce free radicals. In turn, these radicals can start chain reactions and play a major role in the development of cancer, heart disease, ageing, cataracts, and impairment of the immune system in human beings [2]. Human beings on exposure to various organic compounds such as environmental pollutants and drugs can cause cellular damages through metabolic activation of those compounds to highly reactive substances such as ROS (reactive oxygen species). ROS as superoxide radicals, hydroxyl radicals, and hydrogen peroxides derived from the metabolism of oxygen can damage the cell membrane and DNA, leading to mutation which ultimately causes cancer [3]. Diabetes mellitus is a chronic endocrine, metabolic disorder characterized by altered carbohydrates, lipids, proteins, electrolytes, and water metabolism. It includes a group of metabolic diseases characterized by hyperglycemia, in which blood sugar levels are elevated either because the pancreas does not produce enough insulin or cells do not respond to the produced insulin [4]. Diabetes is of insulin-dependent type 1, insulin-resistant type 2 , and gestational.

Therefore, a drug having twofold properties, that is, lowering of blood lipids and glucose together, is in great demand [5]. Higher plants, animals, and microorganisms are found to produce a large number of different protein inhibitors of $\alpha$-amylases and $\alpha$-glucosidases [6]. The drugs acarbose and miglitol are competitive inhibitors of intestinal $\alpha$-glucosidase and reduce the post-prandial digestion and absorption of starch and disaccharides without promoting insulin secretion in diabetes patient [7]. Natural $\alpha$-glucosidase and $\alpha$-amylase inhibitors are used as oral antidiabetic drugs for treating type 2 diabetes with minimal side effects [8-10]. The appearance of drug resistance, as well as the development of undesirable side effects of certain antibiotics, has led to the search of new natural antibiotic agents having high efficacy and less side effect from natural sources. Plants from high 
altitude habitat are a potential source of new and potent anti-microbial agents [11-13]. Thus, this study focused on the chemical and biological activities of some selected medicinal plants collected from Tanahun district of Nepal, which provides scientific validation in using such plants to cure diabetes and infectious diseases.

\section{METHODS}

\section{Chemicals}

Most of the chemicals and solvents used were of laboratory grade. Methanol (Fisher Scientific), acetone (Fischer Scientific), hexane (Merck), and dimethyl sulphoxide; dimethyl sulfoxide (DMSO) (Merck), Folin-Ciocalteu reagent, $\alpha$-amylase enzyme, and acarbose were purchased from the local market. Chemicals and reagents such as gallic acid, quercetin, ascorbic acid, iodine trichloride, 2,2-diphenyl1-picrylhydrazyl (DPPH), $\mathrm{NaNO}_{2}, \mathrm{AlCl}_{3}, \mathrm{KOH}$, and $\mathrm{NaOH}$ were available in the laboratory. Reagents and solvents used during phytochemical analysis were prepared in the laboratory with the chemicals provided in the laboratory.

\section{Equipment}

Electric grinder, mortar, and pestle, digital weighing balance (GT 210), hot air oven (Griffin-Grundy), and rotatory evaporator (Buchi RE 111) with a water bath (Buchi 461), spectrophotometer (WPA, supplied by Philip Harris Shenstone, England), iodine chamber, cuvettes, and micropipettes (Erba BIHOT) were used during this work.

\section{Collection and identification of plant samples}

The plants were collected from the Tanahun district of Nepal. The respective part of the plant used, scientific name, and traditional uses are shown in Table 1. The taxonomic identification of the plants was done at the Central Department of Botany, Tribhuvan University, Kirtipur.

\section{Sample preparation}

The collected plant parts were washed in tap water to remove the contaminants. Then, the plant parts were shade dried. The dried parts were grounded into powder form in an electric grinder and stored in clean plastic bags. The plant extracts were prepared by cold percolation using methanol as a solvent. Fifty grams of powder plant samples were kept separately in clean and dry conical flasks. Three hundred milliliter of methanol was added to each flask and kept for each 3 days with frequent agitation. The mixtures were decanted and filtered with the help of cotton plug and thus obtained filtrates were concentrated in a rotatory evaporator. After complete evaporation of the solvent, the percentage yield for each plant extracts was calculated. The plant extracts were kept in the vial for their phytochemicals analysis and biological activities at $4^{\circ} \mathrm{C}$.

\section{Phytochemical analysis}

The phytochemicals present in different plant extracts were analyzed by following the standard protocol given by Culei [21].

\section{Total flavonoid content}

The total flavonoid content of the plant extracts was estimated by aluminum chloride colorimetric assay taking quercetin as standard [22].

Table 1: List of medicinal plants and their traditional uses

\begin{tabular}{llll}
\hline Code & Scientific name & $\begin{array}{l}\text { Parts } \\
\text { used }\end{array}$ & Traditional uses \\
\hline $\mathrm{MA}_{1}$ & Anisomeles indica & $\begin{array}{l}\text { Whole } \\
\text { plant }\end{array}$ & Urine infection [14] \\
& Achyranthes bidentata & Stem & Worm treatment [15] \\
$\mathrm{MA}_{2}$ & Sphenomeris chinensis & Leaf & Wound healing [16] \\
$\mathrm{MA}_{3}$ & Cleistocalyx operculatus & Bark & Stomachache [17] \\
$\mathrm{MA}_{5}$ & Malvaviscus arboreus & Leaf & Urine infection [18] \\
$\mathrm{MA}_{6}$ & Cissampelos pareira & Stem & Common cold [19] \\
$\mathrm{MA}_{7}$ & Tectaria coadunate & Rhizome & $\begin{array}{l}\text { Toothache, } \\
\text { stomachache [20] }\end{array}$ \\
& & &
\end{tabular}

The average absorbance values obtained for different concentrations of quercetin were used to plot the calibration curve [23]. Total flavonoid content in the plant extract was calculated as, $\mathrm{C}=\mathrm{cV} / \mathrm{m}$, where, $\mathrm{C}=$ total flavonoid content $(\mathrm{mg} \mathrm{QE} / \mathrm{g}), \mathrm{c}=$ concentration of quercetin established from calibration curve in $\mathrm{mg} / \mathrm{ml}$, and $\mathrm{V}=$ volume of the extract $(\mathrm{ml})$.

\section{Statistical analysis}

Data were recorded as absorbance for each concentration, from which the linear correlation coefficient $\left(R^{2}\right)$ value was calculated. The regression equation is given as, $y=m x+c$, using this regression equation, the concentration of the extract was calculated. Thus with the calculated value of the concentration of extract, the flavonoid content was calculated by equation. Where, $\mathrm{y}=$ absorbance of the extract, $\mathrm{m}=$ slope from the calibration curve, $\mathrm{x}=$ concentration of the extract, and $c=$ intercept. The inhibitory concentration was calculated from the regression equation graphically.

\section{Antioxidant activity}

A rapid, simple, and inexpensive method to measure antioxidant capacity involves the use of the free radical DPPH. The ability of different plant extracts to scavenge DPPH free radicals was evaluated by adopting the standard protocol [24].

The percentage of the DPPH free radical scavenging activity was calculated using the following equation:

Radical scavenging $\left.(\%)=\left[\left(\mathrm{A}_{0}-\mathrm{As}\right) / \mathrm{A}_{0}\right]\right]^{*} 100$

Where, $A_{0}=$ Absorbance of the control (DPPH solution + methanol), $\mathrm{A}_{\mathrm{s}}=$ Absorbance of test sample. The $\mathrm{IC}_{50}$ ( $50 \%$ inhibitory concentration) value is indicated as the effective concentration of the sample that is required to scavenge $50 \%$ of the DPPH free radicals. IC $\mathrm{I}_{50}$ values were calculated using the inhibition curve by plotting extract concentration versus the corresponding scavenging effect.

\section{Antidiabetic activity}

The antidiabetic activity of plant extracts was calculated by using the $\alpha$-amylase inhibition assay by adopting the standard protocol with some modifications [25]. The undigested starch due to enzyme inhibition was detected through the blue starch iodine complex detected at $630 \mathrm{~nm}$.

$$
\% \text { inhibition }=\left[\mathrm{Abs}_{2}-\mathrm{Abs}_{1} /\left(\mathrm{Abs}_{4}-\mathrm{Abs}_{3}\right)\right]^{*} 100
$$

Where, $\mathrm{Abs}_{1}=$ absorbance of the incubated mixture containing plant extract, starch, and amylase, $\mathrm{Abs}_{2}=$ absorbance of the incubated mixture containing plant extract and starch, $\mathrm{Abs}_{3}=$ absorbance of an incubated mixture containing starch and amylase, and $\mathrm{Abs}_{4}=$ absorbance of an incubated solution containing starch only. Standard graph was plotted by taking the concentration on the $\mathrm{x}$-axis and percentage inhibition on the y-axis. Based on this graph, $\mathrm{IC}_{50}$ values of each sample were calculated and compared. The species having the lowest $\mathrm{IC}_{50}$ is considered to have the best $\alpha$ amylase enzyme inhibition property or antidiabetic property.

\section{Antibacterial activity}

Antibacterial activity of the plant extracts was evaluated by agar well diffusion method. The bacterial strain Escherichia coli ATCC 25922 and S. aureus ATCC 25923 were grown on nutrient agar media. Effectiveness of antimicrobial substance was evaluated by determination of the zone of inhibition (ZOI) [11]. Four wells were made in each incubated media plates with the help of sterile cork borer no. 6 so, the diameter of a well was $6 \mathrm{~mm}$ and labeled properly. Then, $50 \mu \mathrm{l}$ of the working solution of the plant extract, DMSO as negative control, and ofloxacin as positive control were loaded into the respective wells with the help of micropipette. The plates were then left for half an hour with the lid closed so that the extract diffused into media. The plates were incubated overnight at $37^{\circ} \mathrm{C}$. After $24 \mathrm{~h}$ of incubation, the plates were observed for the presence of inhibition of bacterial growth indicated by a clear zone around the wells. The size of the ZOI was measured and 
the antibacterial activity expressed in terms of the average diameter of the ZOI in millimeters. The absence of the ZOI was interpreted as no activity $[26,27]$.

\section{Toxicity test}

The newly hatched brine shrimp larvae (nauplii) are used for biological screening. This method is rapid, inexpensive, simple, and in-house approach to know the toxic effect of plant extracts. It determines the $\mathrm{LC}_{50}$ values in $\mu \mathrm{g} / \mathrm{ml}$ for the crude extracts. Compounds having $\mathrm{LC}_{50}$ values less than $1000 \mathrm{ppm}$ are considered as pharmacologically active. The toxicity was performed by adopting the standard procedure [17]. $\mathrm{LC}_{50}$ value is the lethal concentration dose required to kill $50 \%$ of the organisms used in bioassay.

\section{Extraction and isolation of compounds}

Cissampelos pareira was selected as the potent plant source to isolate the chemical constituents. About $400 \mathrm{~g}$ of bark powder of the plant was extracted in methanol by cold percolation. The content was filtered and concentrated in a rotatory evaporator. The methanol extract was fractionated by solvent-solvent extraction based on solvent polarity as hexane, dichloromethane, and ethyl acetate. The hexane fraction $(8 \mathrm{~g})$ was adsorbed on silica gel and loaded on to silica (120 g, qualigens, and 60-120 mesh) packed column having an internal diameter of $3 \mathrm{~cm}$ with height $32 \mathrm{~cm}$. The column was initially eluted with hexane and then the gradient of hexane-ethyl acetate of increasing polarity. Different fractions collected through column were analyzed by Thinlayer chromatography (TLC) which guides for changing solvent polarity. The purity of the fractions was tested by TLC and subjected to gas chromatography-mass spectrometry (GC-MS) analysis.

\section{RESULTS AND DISCUSSION}

\section{Phytochemical analysis}

The result of phytochemical analysis for each plant extract is shown in Table 2.

The results showed all most the plant extracts were found rich in secondary metabolites. Flavonoid was present in all most all the plant extracts. On the other side, alkaloids were present in Achyranthes bidentata, saponins in Anisomeles indica, glycosides in all plant extracts, and terpenoids were present in all plant extracts except $A$. indica and Tectaria coadunate.

\section{Total flavonoid content}

Total flavonoid content was estimated by constructing a calibration curve taking quercetin as standard. The results of flavonoid content are shown in Fig. 1. The flavonoid content was expressed as mg QE/g.

The results showed that almost all extracts were found rich in flavonoid content as compared to standard quercetin. A. bidentata exhibited the highest total flavonoid contents (TFC) $5.93 \mathrm{mg}$ QE/g, whereas Malvaviscus arboreus, Cleistocalyx operculatus, C. pareira, T. coadunate, and Sphenomeris chinensis are moderate in flavonoid content. The plant extract of $A$. indica exhibited the lowest TFC content. The results of the present study were found comparable to the previously reported results [26]. Flavonoid compounds are capable of effectively

Table 2: Phytochemical analysis of methanol extract of all plants

\begin{tabular}{llllllll}
\hline Groups of compounds & $\mathbf{M A}_{\mathbf{1}}$ & $\mathbf{M A}_{2}$ & $\mathbf{M A}_{3}$ & $\mathbf{M A}_{\mathbf{4}}$ & $\mathbf{M A}_{5}$ & $\mathbf{M A}_{6}$ & $\mathbf{M A}_{7}$ \\
\hline Basic alkaloids & + & + & - & - & + & + & - \\
Coumarins & - & - & + & - & - & - & + \\
Flavonoids & - & + & + & + & + & + & + \\
Glycosides & + & + & + & + & + & + & + \\
Polyphenols & - & + & + & + & + & + & + \\
Quinones & + & - & - & - & - & + & - \\
Reducing sugars & - & + & - & - & + & + & + \\
Saponins & + & + & - & + & - & + & + \\
Terpenoids & + & + & + & + & + & + & - \\
\hline
\end{tabular}

"+" represents presence and "-" represents absence scavenge free radicals because of their phenolic hydroxyl group. Their antioxidant properties depend on their structure, particularly hydroxyl position in the molecule. Although, quantitative determination of flavonoid compounds in plant extracts is influenced by their structural complexity, diversity, nature of analytical assay method, selection of standard, and presence of interfering substances.

\section{Antioxidant activity}

The results of antioxidant activity are shown in Figs. 2 and 3. Antioxidant activity of plant extract is expressed as percent radical scavenging against concentration. The radical scavenging activity is in a dosedependent manner. With the help of a graph plotting the concentration against the radical scavenging activity, the inhibitory concentration $\left(\mathrm{IC}_{50}\right)$ was calculated and the result is displayed in Fig. 4.

Scavenging of DPPH free radical exhibited by T. coadunate was found to be highest in comparison with other extracts with an $\mathrm{IC}_{50}$ $41.84 \mu \mathrm{g} / \mathrm{ml}$. Similarly, C. pareira and M. arboreus showed moderate antioxidant potential $\mathrm{IC}_{50} 52.03 \mu \mathrm{g} / \mathrm{ml}$ and $76.07 \mu \mathrm{g} / \mathrm{ml}$, respectively. The rest of the plant extracts were poor antioxidants as compared to the standard ascorbic acid. A previous study reported that plant samples rich in phytoconstituents were found responsible for the antioxidant activity [11]. DPPH scavenging assay showed that the plant extracts exhibited dose-dependent percentage scavenging. The antioxidant potential was expressed as the amount of the extract needed to decrease $50 \%$ of the initial concentration of the free radical. The extracts were found to be active antioxidants in the concentration range of $20-100 \mu \mathrm{g} / \mathrm{ml}$ to scavenge free radical. The results of this study were found comparable to the results reported by Ebrahimzadesh et al. (2010) as IC ${ }_{50}$ of H. officinalis L. $311 \pm 14.5 \mu \mathrm{g} / \mathrm{ml}, V$. odorata leaves $245.1 \pm 9.6 \mu \mathrm{g} / \mathrm{ml}, B$. hyrcana leaves $113.1 \pm 8.9 \mu \mathrm{g} / \mathrm{ml}$, and C. speciosum flower $585.6 \pm 21.2 \mu \mathrm{g} / \mathrm{ml}$. The $\mathrm{IC}_{50}$ for BHA, Vitamin C, and quercetin as standard was reported $53.96 \pm 3.1,5.05 \pm 0.1$, and $5.28 \pm 0.2 \mu \mathrm{g} / \mathrm{ml}$, respectively [28].

\section{Antibacterial activity}

The results of antibacterial activity are shown in Table 3.

C. pareira demonstrated the highest antibacterial activity against $S$. aureus with ZOI $12 \mathrm{~mm} /$ well and E. coli with ZOI $9 \mathrm{~mm} /$ well as compared to positive control ofloxacin which showed inhibition toward S. aureus 18 $\mathrm{mm} /$ well and E. coli $14 \mathrm{~mm} /$ well. On the other hand, T. coadunate showed

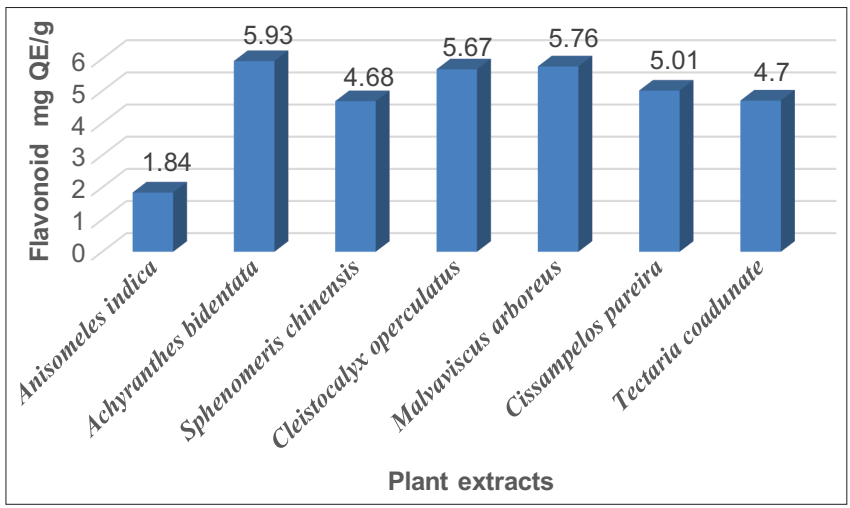

Fig. 1: Flavonoid content in plant extracts

Table 3: Antibacterial activity of plant extracts

\begin{tabular}{|c|c|c|c|}
\hline \multirow[t]{2}{*}{ Bacteria } & \multirow[t]{2}{*}{ Plant extracts } & \multicolumn{2}{|c|}{$\mathrm{ZOI}(\mathrm{mm})$ at $100 \mu \mathrm{g} / \mathrm{ml}$} \\
\hline & & Plant extracts & Positive control \\
\hline E. coli & Cissampelos pareira & 9 & 14 \\
\hline S. aureus & Cissampelos pareira & 12 & 18 \\
\hline E. coli & Tectaria coadunate & - & 14 \\
\hline S. aureus & Tectaria coadunate & 14 & 18 \\
\hline
\end{tabular}




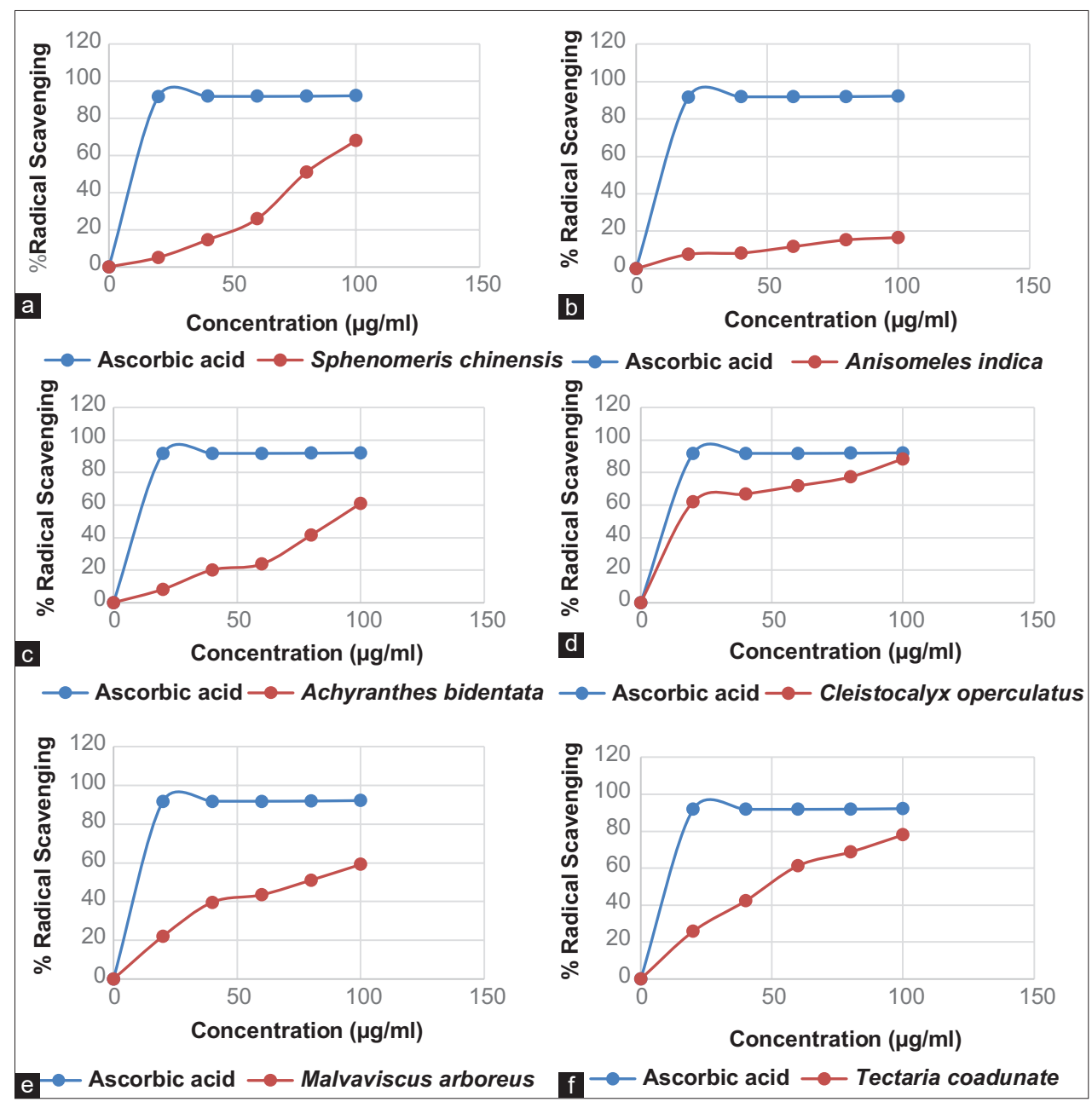

Fig. 2: (a-f) Comparison of percentage radical scavenging against concentration of ascorbic acid and plant extracts

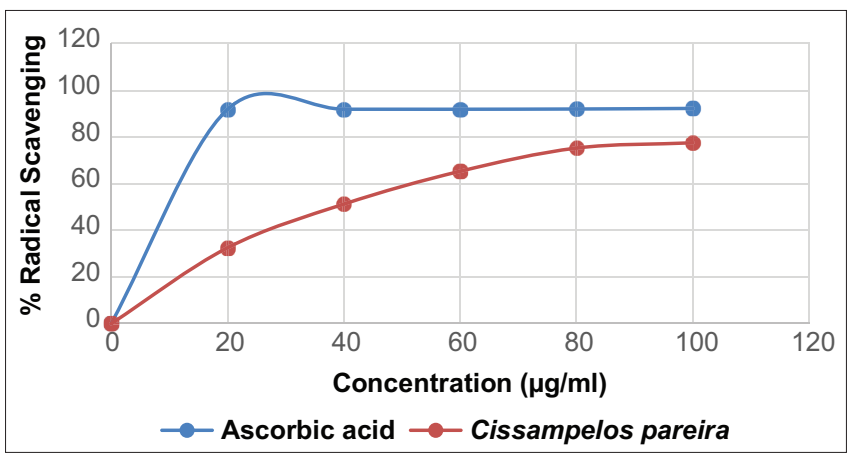

Fig. 3: Radical scavenging against the concentration of Cissampelos pareira

inhibition only against $S$. aureus $14 \mathrm{~mm} /$ well but not against $E$. coli. The rest of the plant extracts were found inactive against these organisms.

\section{Alpha-amylase inhibition activity}

The results of $\alpha$ amylase inhibition are displayed in Fig. 5, where the graph showed $\alpha$ amylase inhibition against the different concentrations of plant extracts.

The results of $\alpha$-amylase inhibitory activity of plant extracts $C$. pareira showed high $\alpha$ amylase inhibition IC $471.68 \mu \mathrm{g} / \mathrm{ml}$ (Fig. 6). The plant extracts of $S$. chinensis, $A$. indica, and M. arboreus showed moderate $\alpha$ amylase enzyme inhibition activity $\mathrm{IC}_{50} 517.59,626.12$, and $952.39 \mu \mathrm{g} /$

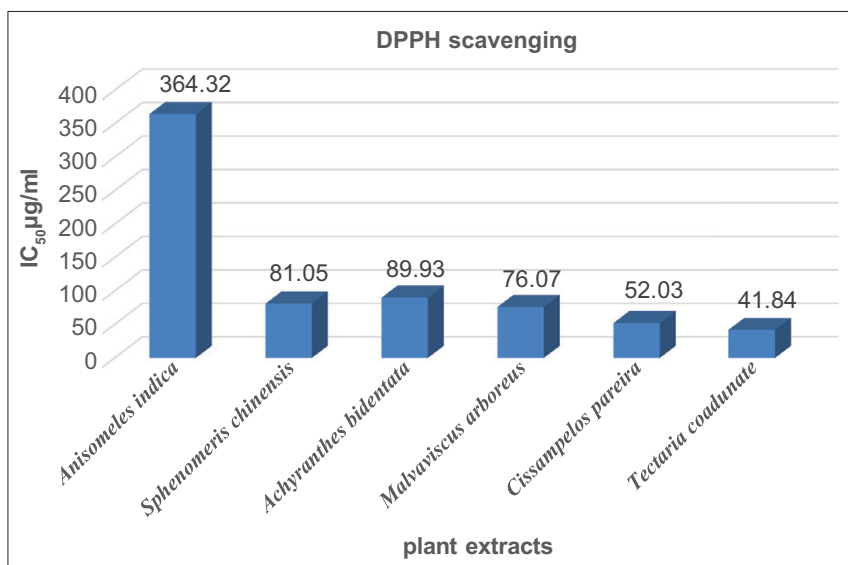

Fig. 4: Antioxidant activity $\left(\mathrm{IC}_{50}\right)$ values of active plant extracts

$\mathrm{ml}$, respectively. The rest of the plant extracts exhibited poor $\alpha$ amylase enzyme inhibition as compared to the standard acarbose. The results of this study showed some similarities to the results reported by the previous researchers for the antidiabetic activity of $C$. pareira extract and some other medicinal plants [26].

\section{Toxic effect}

The degree of lethality was found to be directly proportional to the concentration of the extracts that are maximum mortalities of the brine shrimp larvae that took place at the concentration of $1000 \mu \mathrm{g} / \mathrm{ml}$ 
Table 4: Fractions collected in column chromatography and TLC report

\begin{tabular}{|c|c|c|c|c|}
\hline Solvent system & Fractions & Eluent (ml) & TLC solvent system & TLC spots \\
\hline $100 \%$ hexane & $1-10$ & 1000 & $2 \%$ EtOAc in hexane & No spots \\
\hline $1 \%$ EtOAc in hexane & $11-20$ & 1000 & $2 \%$ EtOAc in hexane & No spots \\
\hline $3 \%$ EtOAc in hexane & $21-30$ & 1000 & $5 \%$ EtOAc in hexane & No spots \\
\hline $5 \%$ EtOAc in hexane & $31-40$ & 1000 & $8 \%$ EtOAc in hexane & Single spot \\
\hline $10 \%$ EtOAc in hexane & $41-50$ & 1000 & $15 \%$ EtOAc in hexane & Tailing \\
\hline $13 \%$ EtOAc in hexane & $51-60$ & 1000 & $15 \%$ EtOAc in hexane & Single spot \\
\hline $20 \%$ EtOAc in hexane & $61-70$ & 1000 & $25 \%$ EtOAc in hexane & Tailing \\
\hline $50 \%$ EtOAc in hexane & $81-90$ & 1000 & $60 \%$ EtOAc in hexane & Tailing \\
\hline $70 \%$ EtOAc in hexane & $91-100$ & 1000 & $80 \%$ EtOAc in hexane & Tailing \\
\hline $100 \%$ EtOAc & $101-110$ & 1000 & $2 \% \mathrm{MeOH}$ in EtOAc & Tailing \\
\hline $1 \% \mathrm{MeOH}$ in EtOAc & $111-115$ & 500 & $5 \% \mathrm{MeOH}$ in EtOAc & Single spot \\
\hline $5 \% \mathrm{MeOH}$ in EtOAc & $116-120$ & 500 & $10 \% \mathrm{MeOH}$ in EtOAc & Tailing \\
\hline $20 \% \mathrm{MeOH}$ in EtOAc & $121-125$ & 500 & $25 \% \mathrm{MeOH}$ in EtOAc & Tailing \\
\hline $50 \% \mathrm{MeOH}$ in EtOAc & $126-130$ & 500 & $60 \% \mathrm{MeOH}$ in EtOAc & Tailing \\
\hline
\end{tabular}

TLC: Thin layer chromatography

Table 5: Peak report (GC-MS analysis)

\begin{tabular}{lllll}
\hline Peak & Retention time & Area $\%$ & Name & Base m/z \\
\hline 1 & 9.477 & 7.95 & 3-Isopropoxy-1,1,1,7,7,7-hexamethyl-3,5,5-tris (trimethylsiloxy) tetrasiloxane & 73.10 \\
2 & 10.841 & 4.88 & Cyclooctasiloxane, hexadecamethyl ester & 73.05 \\
3 & 12.779 & 7.03 & Pentadecanoic acid, 14-methyl-, methyl ester & 74.05 \\
4 & 13.942 & 3.79 & 9,12 -Octadecadienoicacid, methyl ester & 67.10 \\
5 & 15.504 & 71.22 & Alpha-tocopherol & 165.15 \\
6 & 19.504 & 5.14 & 4,22-Stigmastadiene-3-one & 69.10 \\
\hline
\end{tabular}

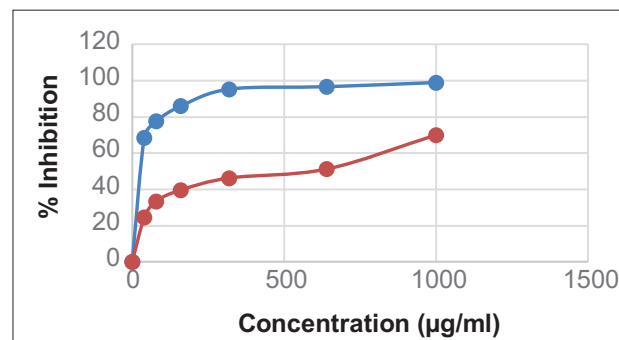

a

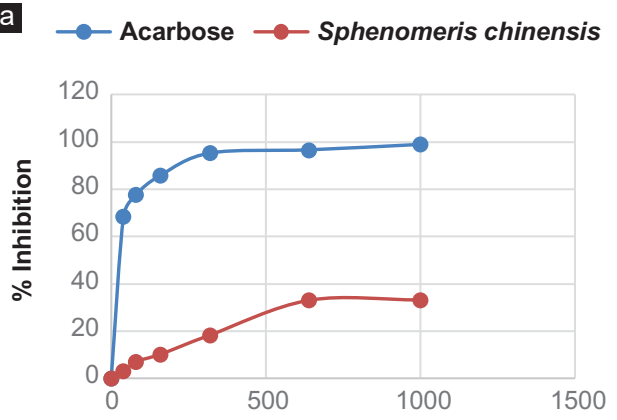

C

Concentration $(\mu \mathrm{g} / \mathrm{ml})$

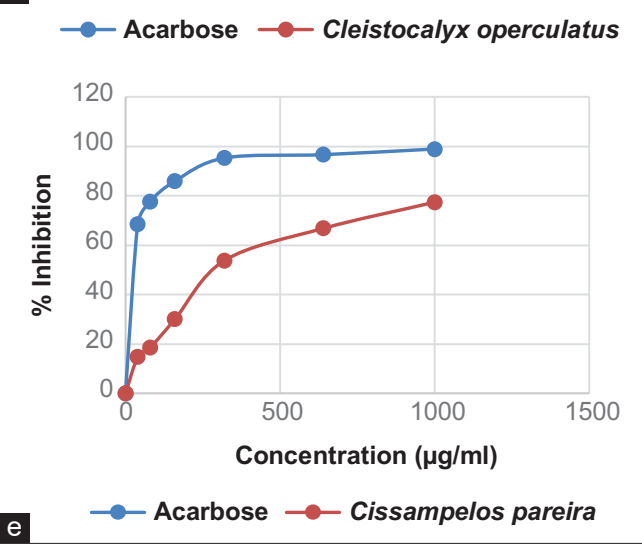

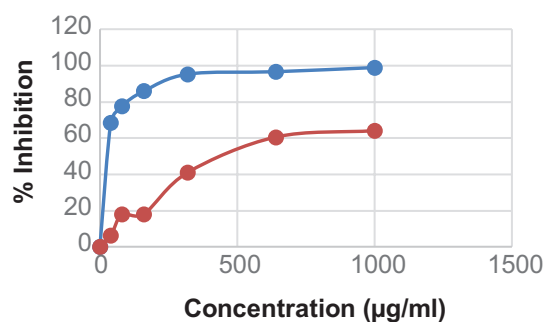

b
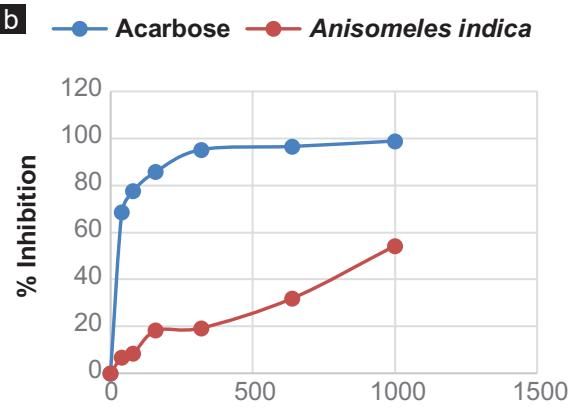

d

Concentration $(\mu \mathrm{g} / \mathrm{ml})$
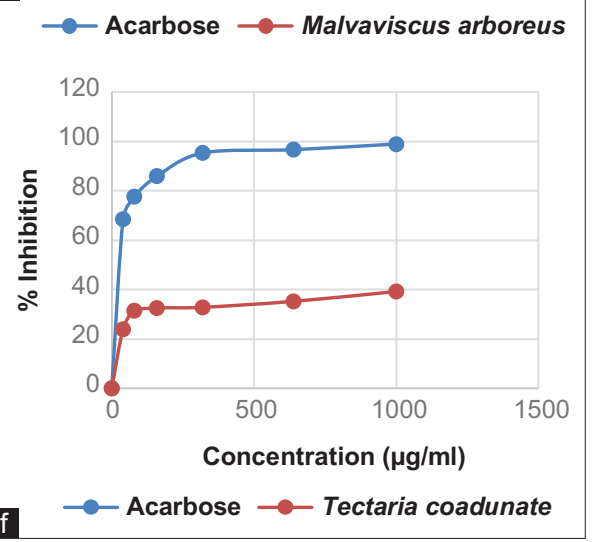

Fig. 5: (a-f) Percent inhibition of $\alpha$-amylase against the concentration of plant extract as compared to acarbose 


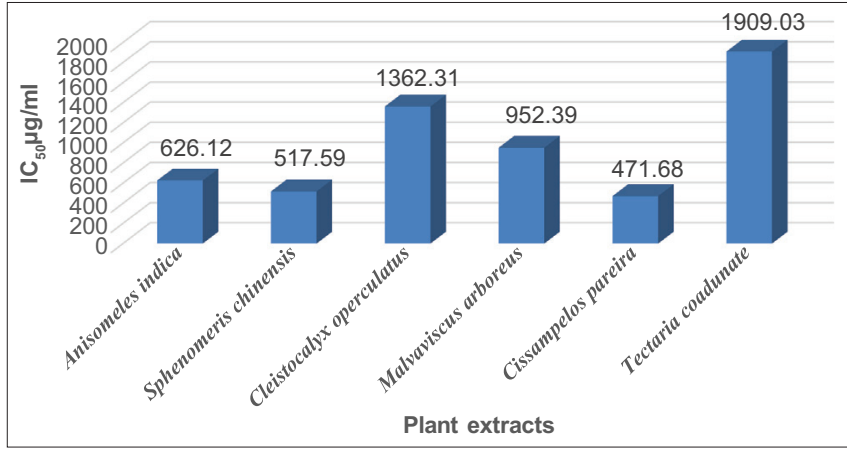

Fig. 6: Comparison of $\mathrm{IC}_{50}$ values for $\alpha$ amylase inhibition of different plant extracts

and least mortalities were at $10 \mu \mathrm{g} / \mathrm{ml}$. Those having $\mathrm{LC}_{50}$ values $<1000 \mu \mathrm{g} / \mathrm{ml}$ are supposed to be pharmacologically active. The extract of $A$. bidentata was found cytotoxic against brine shrimps showing $\mathrm{LC}_{50}$ $15.49 \mu \mathrm{g} / \mathrm{ml}$ whereas $C$. operculatus with $\mathrm{LC}_{50} 31.63 \mu \mathrm{g} / \mathrm{ml}$ showing mild toxic toward brine shrimp larvae. On the other side, $A$. indica, S. chinensis, C. pareira, and T. coadunate were found nontoxic.

Isolation of chemical compounds and GC-MS analysis

The chemical constituents were isolated from the active plant extract C. pareira which was selected based on biological activity. The list of hexane fractions collected after the column chromatography was analyzed by thin-layer chromatography. The list of fractions collected after elution is shown in Table 4.

Fraction collected at 5\% ethyl acetate in hexane was yellow viscous seems single spot in TLC was subjected for GC-MS analysis. The fraction showed the following results.

Six compounds were detected by GC-MS analysis of partially purified fraction collected in $5 \%$ ethyl acetate in hexane. The list of compounds with peak report is shown in Table 5. Out of six compounds, the alphatocopherol is the major compound with a high peak area $(71.22 \%)$ having a base $\mathrm{m} / \mathrm{z}$ ratio 165.15 . The molecular formula of alphatocopherol can be established as $\left(\mathrm{C}_{29} \mathrm{H}_{50} \mathrm{O}_{2}\right)$. The structure of alphatocopherol is shown in Fig. 7.

\section{CONCLUSION}

The phytochemical analysis showed that plants are the rich sources of secondary metabolites from which the active chemical compounds can be isolated. The plant extract $A$. bidentata found rich in flavonoid content. Out of seven medicinal plants, extracts of T. coadunate, C. pareira, and M. arboreus showed promising antioxidant activity as compared to ascorbic acid. The plant extracts of C. pareira and S. chinensis exhibited the strong $\alpha$ amylase inhibitory activity as compared to the standard acarbose. The plant extracts of $C$. pareira and T. coadunate showed significant antibacterial activity against $E$. coli and $S$. aureus. The toxic effect against brine shrimp nauplii was shown by $A$. bidentata and C. operculatus, whereas the rest of the plant extracts do not show any toxic effect. The partially purified fraction of C. pareira showed the presence of six compounds indicated by GC-MS analysis. Among these six compounds, $\alpha$-tocopherol showed a high percentage peak area with base m/z 165 indicates the major compound. In this way, the study provides partial scientific support for the traditional application of these medicinal plants to cure diabetes and bacterial infections. Further studies are needed to isolate the active natural conpounds for establish the precise mechanism of action by in-vivo experiments.

\section{ACKNOWLEDGMENT}

Authors are grateful to the Central Department of Chemistry, Tribhuvan University, for providing laboratory facilities and to the Central Department of Botany, Tribhuvan University, for identification of plants. We are thankful to the National Forensic Science Laboratory, Lalitpur, for GC/MS analysis.

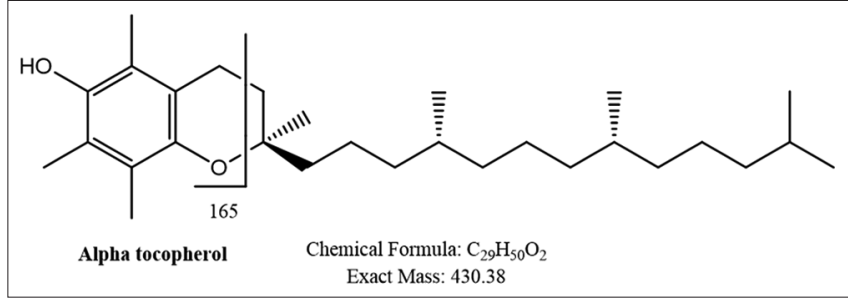

Fig. 7: Major compound from partially purified fraction of Cissampelos pareira extract

\section{AUTHORS' CONTRIBUTIONS}

Sharma et al. wrote the manuscript, whereas Md Amit carried out the laboratory work. Both the authors read and approved the final manuscript.

\section{FUNDING}

Nil.

\section{CONFLICTS OF INTEREST}

All authors have no conflicts of interest.

\section{REFERENCES}

1. Malla SB, Shakya PR. Medicinal plants. In: Majupuria TC, editor. Nepal Nature Paradise. Bangkok: White Lotus; 1999. p. 261-36.

2. Bhuiyan M, Hoque M, Hossain S. Free radical scavenging activities of Zizyphus mauritiana. World J Agric Sci 2009;5:318-4.

3. Jevas OC. The Role of reactive oxygen species and antioxidants in oxidative stress. Int J Res Pharm Biosci 2016;3:1-8.

4. West IC. Radical and oxidative stress in diabetes. Diabetic Med 2000;17:171-9.

5. Narender T, Shweta S, Tiwari P, Reddy KP, Khaliq T, Prathipati P, et al. antihyperglycemic and antidyslipidemic agent from Aegel marmelos. Bioorg Med Chem Lett 2007;17:1808-3.

6. Bhat M, Zinjarde SS, Bhargava SY, Ravikumar A, Joshi BN. Antidiabetic Indian plants: A good source of potent amylase inhibitors. J Evid Based Complement Altern Med 2008;2011:1-6.

7. Davis SN, Granner DK. Pharmacological Basis of Therapeutics. New York: Pergamon Press; 1996. p. 1487-30.

8. Chakrabarti R, Rajagopalan R. Diabetes and insulin resistance associated disorders: Disease and therapy. Curr Sci 2002;83:1533-5

9. Bray GA, Greenway FL. Current and potential drug for treatment of obesity. Endocr Rev 1999;20:805-70.

10. Nair SS, Kavrekar V, Mishra A. In vitro studies on alpha-amylase and alpha-glucosidase inhibitory activities of selected plant extracts. Eur J Exp Biol 2013;3:128-4.

11. Cavalieri SJ, Rankin ID, Harbeck RJ, Sautter RL. Manual of Antimicrobial Susceptibility Testing. Washington, DC: American Society for Microbiology; 2005.

12. Zaidan MR, Rain NA, Badrul AR, Adlin A, Norazah A, Zakiah I. In vitro screening of five local medicinal plants for antibacterial activity using disc diffusion method. Trop Biomed 2005;22:165-5.

13. Kumar S, Pandey AK. Chemistry and biological activities of flavonoids: An overview. Sci World J 2013;2013:1-16.

14. Wang YC, Huang TL. Screening of anti-Helicobacter pylori Herbs deriving from Taiwanese folk medicinal plants. FEMS Immunol Med Microbiol 2005;43:295-5.

15. Indian Council of Medical Research. Review on Indian Medicinal Plants. Vol. 2. New Delhi: Indian Council of Medical Research; 2004. p. 143.

16. Upreti K, Jalal JS, Lalit M, Tewari LM, Joshi GC, Pangtey YP, et al. Ethnomedicinal uses of pteridophytes of Kumaun Himalaya, Uttarakhand India. J Am Sci 2009;5:167-3.

17. Duong Van N. Medicinal Plants of Vietnam, Cambodia, and Laos. Santa Monica, CA: Mekong Printing; 1993.

18. Zokhroof Y, Sharif T, Tasnuva S, Ridwan BR, Sikder MA. Bioactivities of Malvaviscus arboreus var. Drummondii and Phyllanthus reticulatus Poir. Dhaka Univ J Pharm Sci 2014;13:143-4.

19. Taylor L. Tropical Plant Database Entry for ABUTA-Cissampelos pareira. Tamil Nadu: Rain-Tree Publisher; 1996.

20. Kamble SY, Patil SR, Sawant PS, Sawant S, Pawar SG, Singh EA. Studies on plant used in traditional medicine by Bhilla tribe of 
Maharashtra. Indian J Tradit Know 2010;9:591-7.

21. Culei I. Comparative antioxidant activity of individual herbal components used in ayurvedic medicine. Phytochemistry 2003;63:97-7.

22. Bag GC, Grihanjali PD, Bhaigyabati T. Assessment of total flavonoid content and antioxidant activity of methanolic rhizome extract of three Hedychium species of Manipur valley. Int J Pharm Sci Rev Res 2015;30:154-5.

23. Jamuna S, Paulsamy S, Karthika K. Screening of in vitro antioxidant activity of methanolic leaf and root extracts of Hypochaeris radicata $\mathrm{L}$. (Asteraceae). J Appl Pharm Sci 2012;2:149-5.

24. Kusano R, Ogawa S, Matsuo Y, Tanaka T, Yazaki Y, Kouno I. $\alpha$-amylase and lipase inhibitory activity and structural characterisation of acacia bark proanthocyanidins. J Nat Prod 2011;74:119-9.

25. Meyer BN, Ferrigni NR, Putnam JE, Jacobsen LB, Nichols DE,
McLaughlin JL. Brine shrimp: A convenient general bioassay for active plant constituents. J Med Plant Res 1982;45:31-3.

26. Chandra S, Khan S, Avula B, Lata H, Yang MH, Elsohly MA, et al. Assessment of total phenolic and flavonoid content, antioxidant properties, and yield of aeroponically and conventionally grown leafy vegetables and fruit crops: A comparative study. J Evid Based Complement Alternat Med 2014;2014:253875.

27. Maduram A, Kamaraj R. To study the antibacterial activity of various extracts of Clausena dentata Wild. Roem. Asian J Pharm Clin Res 2020;13:69-4.

28. Ebrahimzadeha MA, Nabavia SM, Nabavi SF, Bahramian F, Bekhradnia AR. Antioxidant and free radical scavenging activity of $H$. officinalis 1. Var. angustifolius, V. odorata, B. hyrcana and C. speciosum. Pak J Pharm Sci 2010;23:29-34. 